\title{
Clinical and functional assessment of patients with idiopathic pulmonary fibrosis: results of a 3 year follow-up
}

\author{
C. Agustí, A. Xaubet, A.G.N. Agustí, J. Roca, J. Ramirez, R. Rodriguez-Roisin
}

Clinical and functional assessment of patients with idiopathic pulmonary fibrosis: results of a 3 year follow-up. C. Agustí, A. Xaubet, A.G.N. Agustí, J. Roca, J. Ramirez, R. Rodriguez-Roisin. CERS Journals Ltd 1994.

ABSTRACT: The purpose of this study was to analyse the information provided by different techniques used in the assessment of patients with idiopathic pulmonary fibrosis (IPF) and their role in the prediction of lung function decline with the disease.

Twenty seven subjects with IPF $(55 \pm 14($ mean \pm SD) yrs) were studied at the initial staging. Nineteen of them $(70 \%)$ were included in a follow-up over 3 yrs (32 \pm 6 months), whilst the remaining 8 patients were lost to follow-up. During the period of the study, 6 of the 19 patients died.

A significant correlation between diffusing capacity of the lungs for carbon monoxide (DLCo) (and carbon monoxide transfer coefficient $\left(\mathrm{KCO}_{\mathrm{C}}=\mathrm{DLCO} / \mathrm{alveolar}\right.$ volume $\left.\left(\mathrm{V}_{\mathrm{A}}\right)\right)$ and the increase in alveolar-arterial oxygen tension difference $\left(\mathrm{A}-\mathrm{aPo}_{2}\right)$ during exercise $\left(\triangle \mathrm{A}-\mathrm{aPo}_{2}\right)$ was observed at diagnosis $(\mathrm{r}=-\mathbf{0 . 5 8})$. Despite the treatment with prednisone $\left(1 \mathrm{mg} \cdot \mathrm{kg}^{-1}\right.$ daily during 4 weeks, tapered to an individualized maintenance daily dose of $15-30 \mathrm{mg}$ ), the 13 patients controlled throughout the whole period of the study showed a marked impairment in lung volumes; forced vital capacity (FVC) $-0.46 \pm 0.09 l$, from $69 \pm 16$ to $52 \pm 11 \%$ of predicted, and total lung capacity (TLC) $-0.39 \pm 0.11 l$, from $75 \pm 16$ to $62 \pm 14 \%$, and in DLCo $-0.6 \pm 0.2$ mmol.min ${ }^{-1} \cdot \mathrm{kPa}^{-1}$, from $56 \pm 15$ to $47 \pm 18 \%$, predicted. By contrast, both mean arterial oxygen tension $\left(\mathrm{PaO}_{2}\right)$ and $\mathrm{A}-\mathrm{aPo}_{2}$ at rest remained unchanged throughout the 3 yrs follow-up. The $\triangle \mathrm{A}-\mathrm{aPo}_{2}$ at the initial staging correlated with the increase in $\mathrm{A}-\mathrm{aPo}_{2}$ at rest measured both at 20 months and at the end of the follow-up $(r=0.79$ and $r=0.76$, respectively). Similarly, the initial Kco correlated with the increase in $\mathrm{A}-\mathrm{aPo}_{2}$ at rest measured at the end of the follow-up ( $\left.r=-0.65\right)$.

Although the number of patients evaluated is small, this study suggests that both the single-breath $\mathrm{CO}$ diffusing capacity and exercise testing $\left(\triangle \mathrm{A}-\mathrm{aPo}_{2}\right)$ could be useful prognostic indicators of the decline of arterial oxygenation over time in IPF. Eur Respir J., 1994, 7, 643-650.
Servei de Pneumologia i Allèrgia Respiratoria i Departament d'Anatomia Patològica, Hospital Clínic, Facultat de Medicina, Universitat de Barcelona, Barcelona, Spain.

Correspondence: J. Roca

Servei de Pneumologia: Al.lèrgia Respiratoria Hospital Clínic

c/Villarroel 170

Barcelona 08036

Spain

Keywords:

Carbon monoxide diffusing capacity

exercise testing

gas exchange

interstitial lung fibrosis

Received: March 41993

Accepted after revision January 101994

Supported in part, by Grants CICYT 0770/84, Hospital Clínic 1988 and CICYT DEP900136.

C. Agustí received a Research Training Fellowship from The Hospital Clínic, Barcelona.
Idiopathic pulmonary fibrosis (IPF) is a chronic progressive disorder, characterized both by inflammation and fibrosis of the lung parenchyma [1]. The management of patients with IPF is difficult, due to their variable clinical evolution and the inability to accurately assess the severity of the disease and its monitoring [2]. The former can be partially explained by an inadequate characterization of this type of patient. Thus, many investigators have studied patients with lone IPF and those with pulmonary fibrosis associated to collagen disorders as a mixed group [3-8]. However, recent studies seem to support the notion that these two processes are separate entities, with both different pathogenesis and prognosis [9-11].

During the last decade, different procedures, such as bronchoalveolar lavage (BAL), $\mathrm{Ga}^{67}$ lung scanning and exercise tests have been incorporated in the clinical armamentarium to facilitate the assessment of patients with IPF, [12-14] but the results obtained with these techniques have been inconclusive, such that their role as predictors of the long-term evolution of these patients has not, as yet, been established.

The aim of the present study was: 1) to evaluate the information provided by the different tests currently used in the initial staging of patients with IPF; and 2) to analyse their role in the prediction of the decline of lung function with the disease. To this end, we have prospectively studied a homogeneous population of 27 patients with lone IPF; 19 of them being followed for 3 yrs after diagnosis, a period of time longer than that used in most of similar studies [5, 6, 8, 15-17]. Previous studies by our group [18] prompted the hypothesis that the assessment of lung volumes alone may not be sufficient for an adequate clinical evaluation of this type of patients. Measurements of pulmonary gas exchange using single-breath carbon monoxide diffusing capacity (DLCO) and/or exercise testing may add different, useful, complementary information. 


\section{Methods}

The study population included 27 consecutive patients (17 men and 10 women), aged $55 \pm 14$ (mean \pm SD) yrs (range 14-72 yrs), diagnosed over a period of $6 \mathrm{yrs}$. Eight patients were current cigarette smokers, 6 ceased smoking at least 5 yrs before entry into the study, and the remaining 13 patients had never smoked. The diagnosis of IPF was confirmed by open lung biopsy in 14 patients (52\%). Additionally, 2 subjects had a familial type of IPF, and the remaining 11 patients fulfilled the clinical criteria of IPF described by TURNER-WARWICK et al. [4]: 1) widespread, persistent bilateral radiographic shadowing; 2) widespread, persisting crackles; and 3) exclusion of those patients in whom an external fibrogenic agent could be implicated, and those with positive plasma precipitins. Supportive, but not mandatory criteria, were finger clubbing and the presence of a restrictive ventilatory defect. There were no clinical, radiological, or lung function differences between those patients whose diagnosis was performed according to the above mentioned clinical criteria and those with pathological confirmation of the pulmonary disease. None of the patients had clinical or immunological features of connective vascular disease. The study was performed as part of the current diagnostic assessment and outpatient monitoring for interstitial lung disease in our centre. Accordingly, all patients were informed of the characteristics and nature of the procedures carried out and informed consent was obtained from each of them.

\section{Clinical and radiographic assessment}

An extended Epidemiologic Standardization Project (ESP) questionnaire was administered to all patients and a full physical examination was carried out [19]. The severity of dyspnoea was estimated on a standard five point scale (Medical Research Council) (MRC)): grade $0=$ absent; grade $1=$ hurrying on hills or after two flights of stairs; grade $2=$ hurrying on the flat or after one flight of stairs; grade $3=$ breathlessness on minimal exertion; and grade $4=$ breathlessness at rest [20]. Similarly, the presence of inspiratory crackles was graded as follows: grade $0=$ no crackles; grade $1=$ unilateral and localized in posterolateral, lateral or subaxillary areas; grade $2=$ unilateral and widespread crackles; grade $3=$ bilateral and localized; and grade $4=$ bilateral and widespread [20]. Posteroanterior chest roentgenograms were evaluated according to the International Labour Office and Union Internationale Contre le cancer (ILO/UC) 1980 Classification of Pneumoconioses [21] by two blinded and independent readers. Four categories were included: category $0=$ small rounded opacities, absent or less profuse than in category 1 ; category $1=$ small rounded opacities definitely present but few in number; category $2=$ small rounded opacities numerous, the normal lung markings are usually still visible; category $3=$ small rounded opacities very numerous, the normal lung markings are partly or totally obscured. The final assessment of each film represented the average score of these two observers [20].

\section{Pulmonary function tests}

In each patient, forced spirometry and slow vital capacity (HP 47804A Pulmonary System Desk; HewlettPackard, Waltham, Montana, MA, USA), thoracic gas volume and airway resistance (Body test; E. Jaeger, Würzburg, Germany), as well as single-breath carbon monoxide diffusing capacity (DLCO) and carbon monoxide transfer coefficient (KCO) $(\mathrm{KCO}=$ DLCO/alveolar volume (VA)) (Resparameter model A; PK Morgan Ltd, Chatham, Kent, UK) were measured. Dico was corrected for haemoglobin concentration [22]. The reference values used in this study were those obtained in our own laboratory $[23,24]$. In all cases, arterial blood gases at rest were measured (IL 1302 Instrument Laboratories, Milan, Italy). Furthermore, in 20 of the patients the maximal symptom-limited exercise capacity was assessed on a cycloergometer (E. Jaeger, Würzburg, Germany) (7 patients did not perform an exercise test: 3 of them were unable to cycle and the remaining 4 had bone degeneration). We performed a progressive incremental protocol, that consisted of a $20 \mathrm{~W}$ workload increase every minute [25]. The predicted values used in this technique were those reported by JONES et al. [26]. Arterial blood samples, both at rest and duing the maximum tolerated workload, were anaerobically drawn from an indwelling catheter placed in the radial artery of the nondominant side (Seldicath., Plastimed, Saint-Leu-La Foret, Cedex, France). The alveolararterial oxygen tension difference $\left(\mathrm{A}-\mathrm{aPO}_{2}\right)$ was calculated according to the standard formula using the actual respiratory exchange ratio $(\mathrm{R})$. In those paients in whom an exercise test was not carried out, the $\mathrm{A}-\mathrm{aPO}_{2}$ at rest was calculated assuming a respiratory exchange ratio equal to 0.80 .

A restrictive pattern was defined as: forced vital capacity (FVC) $<80 \%$, forced expiratory volume in one second $\left(\mathrm{FEV}_{1}\right) / \mathrm{FVC} \geq 70 \%$, and total lung capacity (TLC) $<80 \%$; Obstructive pattern defined as: $\mathrm{FEV}_{1}$ $<80 \%$ and $\mathrm{FEV}_{1} / \mathrm{FVC} \leq 70 \%$ ).

\section{Ga $a^{67}$ lung scanning}

$\mathrm{Ga}^{67}$ lung scans were performed $48 \mathrm{~h}$ after the i.v. administration of $2-5 \mathrm{mCi}$ of $\mathrm{Ga}^{67}$ citrate, with a gamma camera (4/15 Picker) connected on line to a digital computer. The quantified lung activity was then compared to the hepatic activity and a lung-hepatic index (LHI) obtained. The uptake of gallium-67 in the pulmonary parenchyma was considered abnormally elevated when the LHI was higher than 0.25 [27].

\section{Bronchoalveolar lavage}

Bronchoalveolar lavage (BAL) was performed by flexible fibreoptic bronchoscopy, using a total volume of 150 $\mathrm{ml}$ of $0.9 \%$ sterile saline in three $50 \mathrm{ml}$ aliquots as described previously [20]. The normal differential cell count in our laboratory is: 1) macrophages $94 \pm 2 \%$; 2 ) lymphocytes $4.8 \pm 3 \%$; 3) neutrophils, $1.3 \pm 0.8 \%$; 4) eosinophils $0.1 \pm 0.2 \%$; and 5) mast cells $0 \pm 0$. 


\section{Treatment and follow-up}

At the time of the diagnosis, none of the patients had received steroids. Thereafter, all of them were treated with prednisone, $1 \mathrm{mg} \cdot \mathrm{kg}^{-1}$ daily (not exceeding 100 $\mathrm{mg} \cdot$ day $^{-1}$ ) during 4-6 weeks. Then, prednisone was tapered gradually during the next 6 months to an individual daily maintenance dose of $15-30 \mathrm{mg}$. No patient received immunosuppressor drugs throughout the period of the study. During this period, 6 patients died, 13 completed a follow-up period of 3 yrs ( $32 \pm 6$ months) and the remaining 8 subjects were lost to the followup. The follow-up protocol was based on regular clinical examination, chest X-ray and lung function studies. The latter included forced spirometry, static lung volumes, DLCO, and arterial blood gases at rest.

\section{Statistical analysis}

The results are expressed as mean \pm SD. Mann-Whitney test was used for unpaired analysis and Wilcoxon's test for comparison of paired data. Visual analysis of the plots and both nonparametric (Spearman) and parametric (Pearson) tests were used for correlation analyses with similar results, but only Pearson's correlation coefficients and regression lines are provided. Chisquared tests were used to compare nonquantitative variables. Statistical significance was established when $\mathrm{p}$-value was $\leq 0.05$. No corrections for multiple comparisons are reported in the text.

\section{Results}

\section{On entry to the study}

The individual results of the 27 patients in the first evaluation are shown in tables 1 and 2 . All patients, except one with a familial type of IPF, were symptomatic and most of them had remarkable physical findings. The mean duration of the symptoms at the initial staging was estimated to be $27 \pm 29$ months. Crackles were found in 23 patients $(85 \%)$ and in all but one case were scored 3 or 4 (bilateral crackles). All patients showed different grades of bilateral radiological shadowing ranging from $1-3$ (median 2); only two patients had a profusion score of 3 .

Spirometric data disclosed impairment in either $\mathrm{FEV}_{1}$ and/or FVC in all but one patient (No. 6). A restrictive ventilatory pattern was observed in 17 patients $(63 \%) ; 2$ had an obstructive ventilatory pattern (7\%); and 7 (26\%) a mixed pattern. The patients enrolled in this study showed a moderate to severe impairment of DLCO. Although Dlco was below the lower limit of reference ( $80 \%$ predicted) in 23 out of the 26 patients in whom it was measured (88\%) (including the patient with normal spirometry), only 11 patients $(42 \%)$ displayed a KCO below the lower limit of reference (80\% predicted).

Arterial hypoxaemia at rest $\left(\mathrm{PaO}_{2}<10.6 \mathrm{kPa}\right)$ was present in 20 patients $(74 \%)$, whilst the $\mathrm{A}-\mathrm{aPO}_{2}$ at rest was abnormal $\left(\mathrm{A}-\mathrm{aPo}_{2} \geq 2 \mathrm{kPa}\right)$ in 23 patients $(85 \%)$. As expected, a marked decrease in $\mathrm{PaO}_{2}$ (from 9.9 \pm 1.5 to $7.3 \pm 1.5 \mathrm{kPa})(\mathrm{p}<0.0001)$, with a simultaneous increase in $\mathrm{A}-\mathrm{aPO}_{2}$ (from $4 \pm 1.6$ to $\left.6.4 \pm 1.5 \mathrm{kPa}\right)(\mathrm{p}<0.0001)$ was observed during maximum tolerated exercise. Overall, the oxygen consumption $\left(\mathrm{V}_{2}\right)$ at maximum symptom-limited exercise was $1.06 \pm 0.44 \mathrm{l} \cdot \mathrm{min}^{-1}(53 \pm 15 \%$ of predicted), and heart rate at maximum workload, $127 \pm$ 23 beats $\cdot \min ^{-1}(76 \pm 13 \%$ of predicted). The analysis of the individual data showed that the $\mathrm{A}-\mathrm{aPO}_{2}$ during exercise $\left(\Delta \mathrm{A}-\mathrm{aPO}_{2}\right)$ increased $1.3 \mathrm{kPa}$ or more in 13 patients. Only one patient (No. 10) showed a decrease in $\triangle \mathrm{A}-\mathrm{aPO}_{2}$.

Both $\mathrm{Ga}^{67}$ lung scanning and BAL cell analysis showed a marked inflammatory activity of the lung parenchyma. The $\mathrm{Ga}^{67}$ uptake in lung parenchyma was abnormally increased in all 19 subjects in whom it was measured. The percentage of neutrophils was increased in 17 of the 25 patients in which BAL was performed (68\%). Fourteen patients showed eosinophilia (56\%), and 9 lymphocytosis (36\%). Two (Nos. 7 and 16) of the 3 patients with a normal BAL differential cell count showed an active alveolitis, as reflected by an increase in the $\mathrm{Ga}^{67}$ lung parenchyma uptake.

The analysis of the relationships among the different variables used in the initial staging of these patients showed a significant positive correlation between the severity of inspiratory crackles and the percentage of neutrophils in BAL fluid $(\mathrm{r}=0.65 ; \mathrm{p}<0.001)$. It was also shown that both DLCO and KCO were useful functional markers of the severity of gas exchange impairment during exercise. As figure 1 illustrates, the lower the DLCo and Kco the greater the increase in $\mathrm{A}-\mathrm{aPO}_{2}$ during exercise $\left(\Delta \mathrm{A}-\mathrm{aPO}_{2}\right)$.

\section{Follow-up study}

As indicated, 6 of the 27 patients (22\%) enrolled in the study died during the follow-up period. The causes of death were progress of the disease in 5 patients (Nos. 1, 5, 13, 16 and 18), and acute pancreatitis in one patient (No. 10). It is of note that in 2 of the former patients (Nos. 16 and 18), pulmonary tuberculosis was discovered at the time of the necropsy. On the other hand, the 13 patients who concluded the follow-up period showed a marked clinical, radiographic and lung function deterioration at the end of the follow-up. Specifically, a substantial decrease was observed in static lung volumes (FVC $-18 \%, \mathrm{p}<0.001$; TLC: $-11 \%$, $\mathrm{p}<0.002)$ and in Dlco $(-15 \%, \mathrm{p}<0.03)$ (fig. 2) . By contrast, both mean $\mathrm{PaO}_{2}$ and $\mathrm{A}-\mathrm{aPO}_{2}$ at rest remained unchanged. The $\mathrm{A}-\mathrm{aPO}_{2}$ at rest varied $1.3 \mathrm{kPa}$ or more in 9 out of the 13 patients (increased in 7 subjects and decreased in the remaining 2) (fig. 3). It is of note that 10 out of the 13 patients evaluated at 20 months also showed a notable decrease in FVC $(\mathrm{p}<0.01)$, TLC and Dlco ( $\mathrm{p}<0.09$, each) (fig. 2).

Both $\mathrm{KCO}$ and exercise-induced hypoxaemia $\left(\Delta \mathrm{A}-\mathrm{aPO}_{2}\right)$ measured on entry to the study predicted the outcome of pulmonary gas exchange (change in $\mathrm{A}-\mathrm{aPO}_{2}$ at rest) at 
Table 1. - Clinical, radiographic and pulmonary function data at enrolment

\begin{tabular}{|c|c|c|c|c|c|c|c|c|c|c|c|c|}
\hline $\begin{array}{l}\text { Pt. } \\
\text { No }\end{array}$ & $\begin{array}{l}\text { Age } \\
\text { yrs }\end{array}$ & $\begin{array}{l}\text { Open } \\
\text { biopsy }\end{array}$ & $\begin{array}{l}\text { Symptoms } \\
\text { months }\end{array}$ & $\begin{array}{c}\text { Dyspnoea } \\
*\end{array}$ & $\begin{array}{c}\text { Clubbing } \\
*\end{array}$ & $\underset{*}{\text { Crackles }}$ & $\begin{array}{l}\text { Chest } \\
\text { X-Ray * }\end{array}$ & $\begin{array}{l}\text { FVC } \\
l(\% \text { pred })\end{array}$ & $\begin{array}{c}\mathrm{FEV}_{1} / \mathrm{FVC} \\
\%\end{array}$ & $\begin{array}{c}\text { TLC } \\
l(\% \text { pred })\end{array}$ & 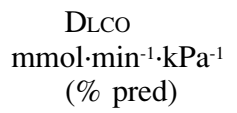 & $\begin{array}{c}\mathrm{KCO} \\
\mathrm{mmol} \cdot \mathrm{min}^{-1} \cdot \mathrm{kPa}^{-1} \cdot l^{-1} \\
(\% \text { pred })\end{array}$ \\
\hline 1 & 59 & $\mathrm{~N}$ & 24 & 1 & $\mathrm{Y}$ & 3 & 2 & 2.2 (49) & 89 & $3.4 \quad(46$ & $4.0 \quad(43)$ & $1.4 \quad(84)$ \\
\hline 2 & 52 & $\mathrm{~N}$ & 48 & 2 & $\mathrm{Y}$ & 4 & 2 & $2.4 \quad(68)$ & 67 & $4.8 \quad(89)$ & $7.5 \quad(80)$ & $2.0(129)$ \\
\hline 3 & 36 & $\mathrm{Y}$ & 36 & 3 & $\mathrm{Y}$ & 0 & 3 & $2.1 \quad(67)$ & 85 & 3.2 (74) & $2.7 \quad(38)$ & $0.9 \quad(50)$ \\
\hline 4 & 41 & $\mathrm{Y}$ & 8 & 1 & $\mathrm{Y}$ & 3 & 2 & $2.8 \quad(72)$ & 77 & $5.0 \quad(91)$ & $4.0 \quad(43)$ & $1.0 \quad(60)$ \\
\hline 5 & 72 & $\mathrm{Y}$ & 19 & 2 & $\mathrm{Y}$ & 3 & 2 & $2.2(70)$ & 83 & $3.6(68)$ & $3.8 \quad(40)$ & 1.3 (97) \\
\hline 6 & 52 & $\mathrm{~N}$ & 18 & 1 & $\mathrm{Y}$ & 4 & 3 & $3.3(81)$ & 76 & $5.0 \quad(98)$ & $5.7 \quad(67)$ & $1.1 \quad(72)$ \\
\hline 7 & 55 & $\mathrm{~N}$ & 24 & 1 & $\mathrm{Y}$ & 1 & 1 & 3.0 & 73 & $5.4 \quad(88)$ & $4.2 \quad(51)$ & $1.0 \quad(56)$ \\
\hline 8 & 65 & $\mathrm{Y}$ & 10 & 2 & $\mathrm{Y}$ & 3 & 2 & $3.0(103)$ & 64 & $4.1 \quad(77)$ & $5.7 \quad(85)$ & 1.5 (77) \\
\hline 9 & 45 & $\mathrm{~N}$ & 42 & 2 & $\mathrm{~N}$ & 4 & 2 & 2.2 (67) & 81 & $3.7 \quad(85)$ & $4.1 \quad(55)$ & $1.5(82)$ \\
\hline 10 & 68 & $\mathrm{Y}$ & 9 & 4 & $\mathrm{~N}$ & 3 & 2 & $2.0 \quad(53)$ & 77 & 3.8 (77) & $4.2 \quad(60)$ & $1.6 \quad(122)$ \\
\hline 11 & 66 & $\mathrm{Y}$ & 48 & 2 & $\mathrm{Y}$ & 4 & 2 & $1.3 \quad(45)$ & 94 & 2.7 (78) & NA & NA \\
\hline 12 & 61 & $\mathrm{~N}$ & 36 & 3 & $\mathrm{Y}$ & 4 & 2 & $1.3 \quad(42)$ & 78 & $2.9 \quad(56)$ & $4.1 \quad(54)$ & 2.1 \\
\hline 13 & 67 & $\mathrm{~N}$ & 24 & 3 & $\mathrm{Y}$ & 4 & 2 & 2.1 & 84 & NA & $2.8 \quad(30)$ & $0.9 \quad(53)$ \\
\hline 14 & 66 & $\mathrm{~N}$ & 24 & 1 & $\mathrm{Y}$ & 3 & 2 & $2.1 \quad(79)$ & 84 & $3.0 \quad(65)$ & 3.2 (47) & $1.1 \quad(65)$ \\
\hline 15 & 67 & $\mathrm{~N}$ & 96 & 1 & $\mathrm{Y}$ & 4 & 2 & $3.0 \quad(78)$ & 80 & $5.5 \quad(83)$ & $3.7 \quad(48)$ & $1.0 \quad(60)$ \\
\hline 16 & 65 & $\mathrm{Y}$ & 3 & 2 & $\mathrm{~N}$ & 3 & 1 & $2.6 \quad(52)$ & 72 & $5.1 \quad(60)$ & $6.2 \quad(63)$ & 1.5 \\
\hline 17 & 59 & $\mathrm{Y}$ & 11 & 1 & $\mathrm{~N}$ & 3 & 1 & $1.9(60)$ & 85 & $2.9 \quad(56)$ & $4.8 \quad(63)$ & $1.8 \quad(102)$ \\
\hline 18 & 54 & $\mathrm{Y}$ & 18 & 3 & $\mathrm{~N}$ & 4 & 2 & 3.2 (66) & 72 & 5.2 (69) & $3.7 \quad(37)$ & $0.8 \quad(45)$ \\
\hline 19 & 45 & $\mathrm{Y}$ & 3 & 3 & $\mathrm{~N}$ & 0 & 2 & $2.0 \quad(65)$ & 85 & $3.6 \quad(75)$ & $4.3 \quad(56)$ & $1.8 \quad(95)$ \\
\hline 20 & 42 & $\mathrm{~N} \dagger$ & 4 & 1 & $\mathrm{Y}$ & 4 & 2 & $2.5 \quad(55)$ & 88 & $4.0 \quad(60)$ & $3.5 \quad(35)$ & $1.0 \quad(59)$ \\
\hline 21 & 27 & $\mathrm{Y}$ & 36 & 1 & $\mathrm{~N}$ & 0 & 2 & $2.8 \quad(62)$ & 60 & 4.6 (77) & $5.9 \quad(56)$ & $1.5(68)$ \\
\hline 22 & 36 & $\mathrm{~N}$ & 6 & 2 & $\mathrm{Y}$ & 3 & 2 & $2.4 \quad(51)$ & 73 & 4.6 (69) & $6.0 \quad(57)$ & $1.8 \quad(86)$ \\
\hline 23 & 14 & $\mathrm{~N} \dagger$ & 0 & 0 & $\mathrm{Y}$ & 0 & 1 & $1.4 \quad(50)$ & 93 & $2.3 \quad(50)$ & $4.0 \quad(52)$ & 2.3 \\
\hline 24 & 67 & $\mathrm{Y}$ & 24 & 4 & $\mathrm{Y}$ & 4 & 2 & $1.4 \quad(50)$ & 84 & 3.1 (64) & $3.3 \quad(51)$ & $1.4 \quad(93)$ \\
\hline 25 & 65 & $\mathrm{Y}$ & 1 & 3 & $\mathrm{~N}$ & 3 & 2 & 2.1 & 76 & $4.3 \quad(55)$ & $6.6(71)$ & 1.9 \\
\hline 26 & 63 & $\mathrm{~N}$ & 90 & 3 & $\mathrm{Y}$ & 4 & 2 & $1.7 \quad(61)$ & 71 & 4.4 (89) & $4.3 \quad(59)$ & $1.6(81)$ \\
\hline 27 & 58 & $\mathrm{Y}$ & 72 & 1 & $\mathrm{~N}$ & 4 & 2 & $2.6 \quad(74)$ & 62 & $5.4 \quad(95)$ & $6.1 \quad(82)$ & 1.7 (95) \\
\hline Mean & 55 & & 27 & 2 & $18 \mathrm{Y} / 9 \mathrm{~N}$ & 3 & 2 & $2.3 \quad(62)$ & 78 & $4.1 \quad(72)$ & $4.6(55)$ & $1.4 \quad(88)$ \\
\hline$\pm \mathrm{SD}$ & 14 & & 29 & 1 & & 1 & 0 & $0.6 \quad(14)$ & 9 & $1 \quad(15)$ & $1.3(14)$ & $0.4 \quad(32)$ \\
\hline
\end{tabular}

*: see text for details; $\dagger$ : familial type IPF. Pt. patient; \% pred: percentage of predicted value; Y: yes; N: no; NA: not available; IPF: idiopathic pulmonary fibrosis; FVC: forced vital capacity; $\mathrm{FEV}_{1}$ : forced expiratory volume in one second; TLC: total lung capacity; DLCO: diffusing capacity of the lungs for carbon monoxide; Kco: carbon monoxide transfer coefficient. 
Table 2. - Main data on gas exchange, gallium-67 lung scanning, BAL cell counts and follow-up period

\begin{tabular}{|c|c|c|c|c|c|c|c|c|c|c|}
\hline \multirow{2}{*}{$\begin{array}{l}\mathrm{Pt} \\
\text { No. }\end{array}$} & \multicolumn{2}{|c|}{$\mathrm{PaO}_{2}$} & \multicolumn{2}{|c|}{$\mathrm{A}-\mathrm{aPO}_{2}$} & \multirow{2}{*}{$\begin{array}{c}\text { Ga-67 } \\
\text { Scanning } \\
\text { LHI }\end{array}$} & \multicolumn{4}{|c|}{ Bronchoalveolar lavage $\%$} & \multirow{2}{*}{$\begin{array}{l}\text { Follow-up } \\
\text { months }\end{array}$} \\
\hline & Rest & Ex & Rest & Ex & & Neut & Lymph & Eos & Mast & \\
\hline 1 & 11.0 & 6.4 & 3.9 & 7.3 & NA & 8 & 2 & 7 & 0 & $10 \dagger$ \\
\hline 2 & 9.4 & 6.8 & 3.9 & 5.6 & NA & 11 & 4 & 0 & 0 & 30 \\
\hline 3 & 12.4 & 6.6 & 2.0 & 7.8 & 0.48 & 5 & 58 & 3 & 0 & 31 \\
\hline 4 & 10.0 & NA & 3.3 & NA & NA & 3 & 19 & 0 & 0 & 33 \\
\hline 5 & 10.4 & 7.0 & 2.8 & 6.5 & 0.45 & 7 & 12 & 0 & 0 & $14 \dagger$ \\
\hline 6 & 9.0 & 8.1 & 3.9 & 4.9 & 0.86 & 9 & 1 & & 4 & 030 \\
\hline 7 & 9.0 & 6.9 & 3.7 & 6.1 & 0.69 & 3 & 1 & & 0 & 032 \\
\hline 8 & 8.0 & NA & 6.9 & NA & 0.53 & 10 & 2 & 0 & 0 & 36 \\
\hline 9 & 13.0 & 11.2 & 0.8 & 3.3 & 0.42 & 9 & 2 & 5 & 1 & NA \\
\hline 10 & 8.4 & 8.8 & 5.6 & 5.0 & 0.69 & 3 & 64 & 0 & 0 & $21 \dagger$ \\
\hline 11 & 9.0 & 7.4 & 5.2 & 7.2 & 0.45 & 9 & 17 & 0 & 0 & NA \\
\hline 12 & 8.0 & NA & 6.0 & NA & 0.82 & 10 & 25 & 1 & 0 & 41 \\
\hline 13 & 7.4 & 5.8 & 6.9 & 7.8 & 0.49 & 10 & 5 & & 4 & $04 \dagger$ \\
\hline 14 & 11.0 & 6.6 & 2.9 & 7.6 & 0.54 & 6 & 6 & 0 & 0 & 30 \\
\hline 15 & 11.7 & 7.4 & 2.0 & 6.5 & 0.60 & 11 & 7 & 4 & 0 & 35 \\
\hline 16 & 9.8 & 7.8 & 3.1 & 5.0 & 0.69 & 3 & 12 & 1 & 0 & $14 \dagger$ \\
\hline 17 & 10.1 & 7.8 & 2.8 & 3.9 & NA & NA & NA & NA & NA & 39 \\
\hline 18 & 9.6 & 5.7 & 5.3 & 8.6 & 0.56 & 8 & 11 & 3 & 2 & $9+$ \\
\hline 19 & 9.6 & NA & 5.7 & NA & 0.61 & 0 & 76 & 5 & 0 & NA \\
\hline 20 & 10.9 & 5.8 & 3.6 & 8.6 & 0.45 & 11 & 6 & 2 & 0 & 30 \\
\hline 21 & 10.4 & 6.9 & 3.7 & 6.9 & NA & NA & NA & NA & NA & NA \\
\hline 22 & 10.5 & 6.6 & 2.8 & 6.0 & NA & 2 & 11 & 0 & 0 & NA \\
\hline 23 & 12.6 & NA & 1.3 & NA & 0.48 & 2 & 3 & 4 & 0 & 37 \\
\hline 24 & 8.9 & NA & 4.4 & NA & NA & 4 & 35 & 3 & 0 & NA \\
\hline 25 & 10.0 & 9.0 & 4.0 & 4.9 & 0.63 & 6 & 55 & 5 & 2 & NA \\
\hline 26 & 7.6 & 5.8 & 5.7 & 6.9 & 0.72 & 7 & 40 & 2 & 1 & 37 \\
\hline 27 & 9.8 & NA & 4.3 & NA & NA & 1 & 8 & 6 & 0 & NA \\
\hline Mean & 9.9 & 7.3 & 4.0 & 6.4 & 0.59 & 6 & 19 & 2 & 0.2 & $34 \dagger$ \\
\hline$\pm \mathrm{SD}$ & 1.5 & 1.5 & 1.6 & 1.5 & 0.13 & 4 & 21 & 2 & 0.5 & $4 \dagger$ \\
\hline
\end{tabular}

$\dagger$ : time elapsed between diagnosis and death; mean \pm SD: only for surviving patients. Pt: patient; LHI: lung-hepatic index; Neut: neutrophils; Lymph; lymphocytes' Eos: eosinophils; Mast: mast cells; Y: yes; N: no; NA: not available; BAL: bronchoalveolar lavage; $\mathrm{PaO}_{2}$ : arterial oxygen tension; $\mathrm{A}-\mathrm{aPO}_{2}$ : alveolar arterial oxygen tension difference.
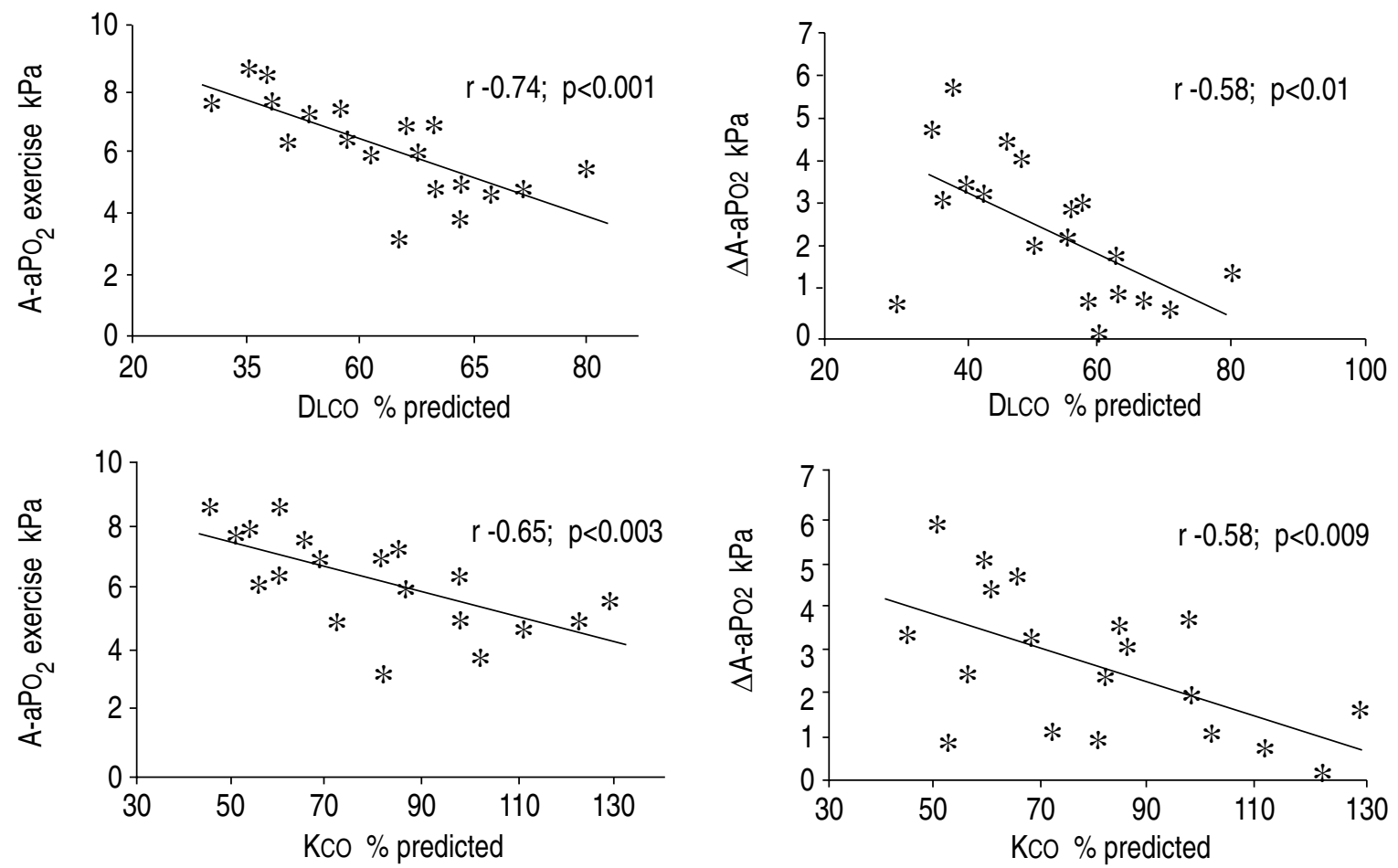

Fig. 1. - Dlco and KCo expressed as $\%$ predicted plotted against $\mathrm{A}-\mathrm{aPo}_{2}$ at maximum tolerated exercise and the increase in $\mathrm{A}-\mathrm{aPO} \mathrm{O}_{2}$ with exercise $\left(\triangle \mathrm{AaPO}_{2}\right)$, respectively. The lower the diffusing capacity for $\mathrm{CO}$, the worse pulmonary gas exchange during exercise. DLco: diffusing capacity of the lung for carbon monoxide; Kco: carbon monoxide transfer coefficient; $\mathrm{A}-\mathrm{aPO}_{2}$ : alveolar arterial oxygen tension difference. 

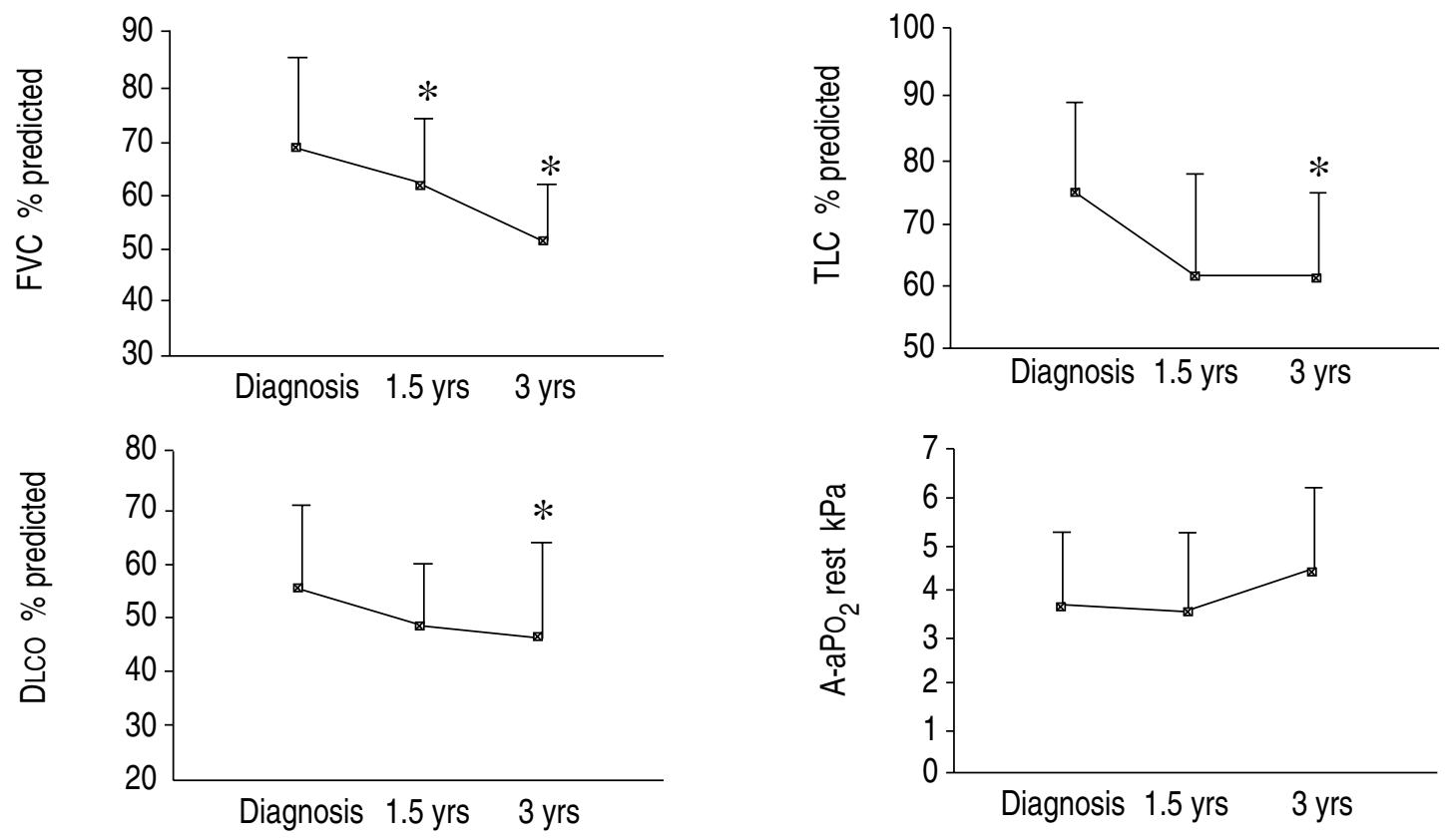

Fig. 2. - Changes of the most representative lung function parameters over time in the 13 patients who concluded the follow-up. While lung volumes and DLco decreased, the $\mathrm{A}-\mathrm{aPO}_{2}$ at rest did not increase. *: (p<0.05) compared to baseline (see text). FVC: forced vital capacity; TLC: total lung capacity. For further abbreviations see legend to figure 1.

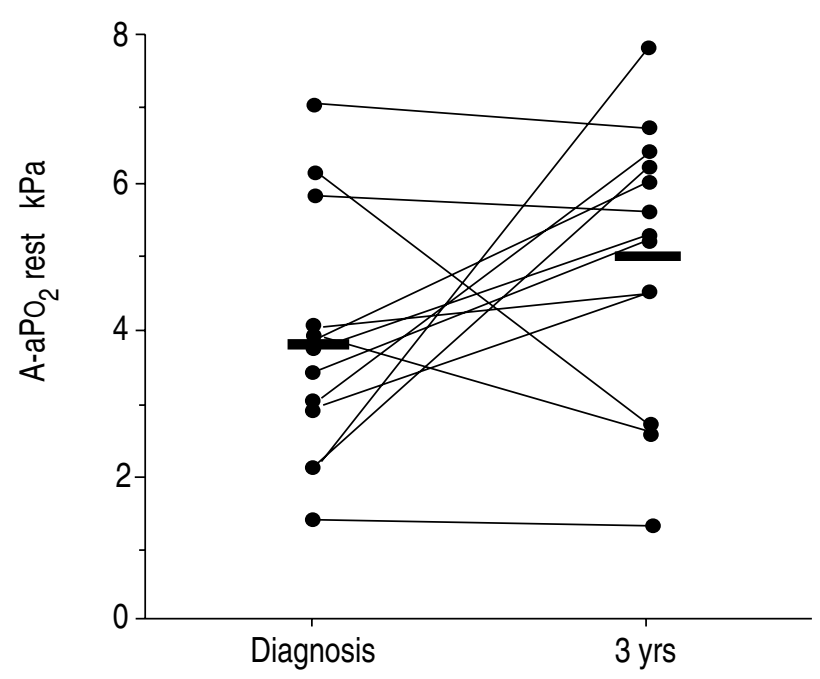

Fig. 3. - Individual evolution of resting $\mathrm{A}-\mathrm{aPo}_{2}$ in the 13 patients who concluded the follow-up. $\mathrm{A}-\mathrm{aPO}_{2}$ : alveolar-arterial oxygen tension difference.

the end of the follow-up (fig. 4). Interestingly, the exercise-induced hypoxaemia $\left(\triangle \mathrm{A}-\mathrm{aPO}_{2}\right)$ at initial staging also correlated with the worsening of resting $\mathrm{A}-\mathrm{aPO}_{2}$ at 20 months $(\mathrm{r}=0.79 ; \mathrm{p}<0.03)$. By contrast, none of the clinical (age at diagnosis, duration of symptoms, presence of crackles, and degree of dyspnoea or crackles), radiographic or spirometric indices measured at the initial staging of the disease, or $\mathrm{Ga}^{67}$ lung scanning and BAL cell count showed a trend to predict the lung function decline during the follow-up.
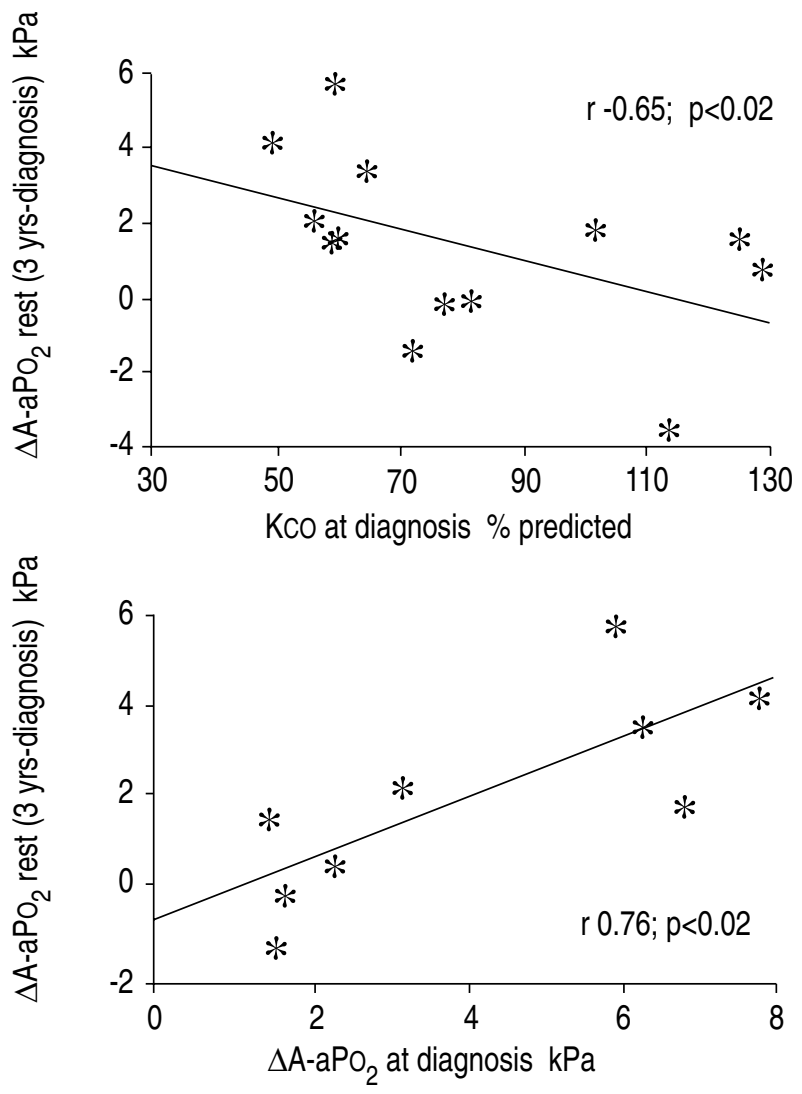

Fig. 4. - $\mathrm{KCO}\left(\%\right.$ predicted) and $\Delta \mathrm{A}-\mathrm{aPo}_{2}$ (exercise-induced) at enrolment plotted against the change in $\mathrm{A}-\mathrm{aPO}_{2}$ at rest throughout the 3 yrs of follow-up. For abbreviations see legend to figure 1 . 


\section{Discussion}

The present study suggests that the measurement of both single-breath $\mathrm{CO}$ diffusing capacity and exerciseinduced hypoxaemia at the initial staging of the disease provides prognostic information of the decline of arterial oxygenation in patients with IPF. Those patients with the lowest $\mathrm{KCO}$ and the highest increase in $\mathrm{A}-\mathrm{aPO}_{2}$ at maximum exercise $\left(\Delta \mathrm{A}-\mathrm{aPO}_{2}\right)$ at the time of the diagnosis experienced the greatest gas exchange deterioration after 3 yrs of follow-up. None of the remaining clinical, radiographic, lung function and inflammatory indices predicted the progress of the IPF during the follow-up period.

Although several authors $[3,14]$ have suggested that the degree of gas exchange impairment during exercise is a good marker of the intensity of the fibrotic changes observed in biopsy specimens of patients with IPF, the prognostic significance of this finding has not, as yet, been ascertained. Our group previously reported [18] a close correlation between the degree of gas exchange impairment during exercise $\left(\Delta \mathrm{A}-\mathrm{aPO}_{2}\right)$ at the initial staging of the disease and each of the following variables: 1) the overall structural derangement of the lung parenchyma; 2) the resistance of the pulmonary vasculature during exercise; and 3) the release of hypoxic pulmonary vasoconstriction upon $100 \% \mathrm{O}_{2}$ breathing. The present study indicates the clinical usefulness of the exercise-induced hypoxaemia at diagnosis, since the patients with the greater impairment of gas exchange during exercise (and presumably more initial fibrotic derangement and lower conductance of the pulmonary vasculature) experienced the worse gas exchange evolution 3 yrs later.

On the other hand, several authors have discouraged the use of the single-breath $\mathrm{CO}$ diffusing capacity for the clinical assessment of the severity of IPF, because of its variability and the number of physiological factors involved in its measurement $[14,28]$. However, the standardization for the DLCO recommended by both the European Community for Coal and Steel [29] and the American Thoracic Society [30] have prompted a substantial improvement of the reproducibility of the DLCO in the clinical laboratory [31]. Our group has recently demonstrated [18] that Deco shows a significant correlation with the main factors determining pulmonary gas exchange during exercise in patients with IPF, namely ventilation-perfusion inequality, alveolar to end-capillary $\mathrm{O}_{2}$ diffusion limitation, and pulmonary haemodynamics, some of which are invariably related to the severity of the underlying pulmonary derangement. In this respect, it is interesting to note that the above mentioned correlations between gas exchange impairment during exercise and degree of pulmonary derangement in biopsy specimens was also observed for Dlco/VA ratio [18].

The prognostic role of DLCo in pulmonary fibrosis had been previously suggested by TUKIANEN et al. [17]. However, these investigators included patients with associated connective diseases, and there is increasing evidence that the natural history of pulmonary fibrosis might be different whether or not an associated connective disease is present [9-11].

In order to confirm the prognostic information of exercise tests and DLCo in patients with IPF, it would have been interesting to know whether or not these variables also predicted the mortality observed in the present series. Unfortunately, 3 of the 6 patients who died had other concurrent diseases, which decisively influenced their fatal evolution. In either case, the mean KcO of the 5 patients who died due to the progression of IPF was lower than that observed in the 13 patients who survived $(75 \pm 25$ vs $81 \pm 27 \%$ pred), but no statistical significance was reached. A potential criticism of the present study is, however, that the predictive role of DLCo and exercise testing was demonstrated in a rather small number of subjects who fully completed the follow-up period. Although we carried out multiple comparisons between variables without appropriate corrections of the reported p-values, the correlations among pulmonary gas exchange markers (DLCO and $\Delta \mathrm{A}-\mathrm{aPO}_{2}$ ) at diagnosis and the increase in $\mathrm{A}-\mathrm{aPO}_{2}$ throughout the follow-up do not seem to be spurious. Such correlations are not weak and, more importantly, are not meaningless from a physiological viewpoint. The generalization of these results, as well as the precise clinical use of these two tests (DLCo and exercise testing) in the routine evaluation of the patients, should warrant future studies in a larger independent population of patients with lone IPF.

Our results also indicate that the assessment of commonly accepted markers of the inflammatory activity of the lung parenchyma, such as gallium-67 lung scanning, do not facilitate the clinical management of patients with IPF. This technique does not seem to provide further information in the decision-making process at the initial staging of the disease, nor does it play a predictive role in the decline of lung function throughout the follow-up period. The lack of a predictive role was also observed for the BAL differential cell count. Discrepancies among studies using gallium-67 lung scanning and BAL fluid differential cell count can be explained by different factors $[5,6,8,15-17]$. Frequently, different types of interstitial lung diseases have been analysed together. Likewise, different standardization procedures in the BAL differential cell count can be an additional cause of variability. Furthermore, alveolitis is a dynamic phenomenom influenced by many factors, such as corticosteroid therapy or smoking habits [7, 32].

In summary, the present study suggests that the assessment of pulmonary gas exchange at diagnosis using single-breath CO diffusing capacity and/or exercise testing may predict the decline of arterial oxygenation $\left(\mathrm{A}-\mathrm{aPO}_{2}\right)$ over time due to the disease. Although these tests may provide useful prognostic indicators in the clinical evaluation of patients with IPF, their roles in predicting individual treatment response and survival are currently unknown.

Acknowledgements: The authors are indebted to F. Burgos, M-T. Solé, C. Gistau, M-T. Lecha, M-T. Simó, M. Carrión and C. Argaña for their technical expertise. 


\section{References}

1. Jackson LK. Idiopathic pulmonary fibrosis. Clin Chest Med 1982; 3: 579-592.

2. Raghu G. Idiopathic pulmonary fibrosis. A rational clinical approach. Chest 1987; 92: 148-154.

3. Carrington CB, Gaensler EA, Coutu RE, Fitzgerald MX, Gupta RG. Natural history and treated course of usual and desquamative interstitial pneumonia. $N$ Engl J Med 1978; 298: 801-811.

4. Turner-Warwick M, Burrows B, Johnson A. Cryptogenic fibrosing alveolitis: clinical features and their influence on survival. Thorax 1980; 35: 171-180.

5. Haslam PL, Turton CWG, Lukoszek A, et al. Bronchoalveolar lavage fluid cell counts in cryptogenic fibrosing alveolitis and their relation to therapy. Thorax 1980; 35: $328-339$.

6. Rudd RM, Haslam PL, Turner-Warwick M. Cryptogenic fibrosing alveolitis. Relationships of pulmonary physiology and bronchoalveolar lavage to response to treatment and prognosis. Am Rev Respir Dis 1981; 124: 1-8.

7. Turner-Warwick M, Haslam PL. The value of serial bronchoalveolar lavages in assessing the clinical progress of patients with cryptogenic fibrosing alveolitis. Am Rev Respir Dis 1987; 135: 26-34.

8. Peterson MW, Monick M, Hunninghake GW. Prognostic role of eosinophils in pulmonary fibrosis. Chest 1987; 92: 51-56.

9. Agustí C, Xaubet A, Roca J, Agustí AGN, RodriguezRoisin R. Interstitial pulmonary fibrosis with and without associated collagen vascular disease: results of a 2 years follow-up. Thorax 1992; 47: 1035-1040.

10. Nagai S, Fujimura N, Hirata T, Izumi T. Differentitation between idiopathic pulmonary fibrosis and interstitial pneumonia associated with collagen vascular diseases by comparison of the ratio of OKT4+ cells and OKT8+ cells in BALF T-lymphocytes. Eur J Respir Dis 1985; 67: 1-9.

11. Owens GR, Paradis IL, Gryzan S, et al. Role of inflammation in the lung disease of systemic sclerosis: comparison with idiopathic pulmonary fibrosis. $J \mathrm{Lab}$ Clin Med 1986; 107: 253-260.

12. Hunninghake GW, Gadek JE, Kawanami O, Ferrans VJ, Crystal RG. Inflammatory and immune processes in the human lung in health and disease: evaluation by bronchoalveolar lavage. Am J Pathol 1979; 97: 149-206.

13. Line BR, Fulmer JD, Reynolds JY, et al. Gallium-67 citrate scanning in the staging of idiopathic pulmonary fibrosis: correlation with physiologic and morphologic features and bronchoalveolar lavage. Am Rev Respir Dis 1978; 118: 355-365.

14. Fulmer JD, Roberts WC, Von Gal E, Crystal RG. Morphologic-physiologic correlates of the severity of fibrosis and degree of cellularity in idiopathic pulmonary fibrosis. J Clin Invest 1979; 63: 665-676.

15. Crystal RG, Gadek JE, Ferrans CJ, Fulmer FD, Line BR, Hunninghake GW. Interstitial lung disease: current concepts of pathogenesis, staging and therapy. Am J Med 1981; 70: 542-568.

16. Watters LC, Schwarz MI, Cherniack RM, et al. Idiopathic pulmonary fibrosis. Pretreatment broncho- alveolar lavage cellular constituents and their relationships with lung histopathology and clinical response to therapy. Am Rev Respir Dis 1987; 135: 696-704.

17. Tukianen P, Taskinen E, Holsti P, Korhola O, Valle M. Prognosis of cryptogenic fibrosing alveolitis. Thorax 1983; 38: 349-355.

18. Agustí AGN, Roca J, Gea J, Wagner PD, Xaubet A, Rodriguez-Roisin R. Mechanisms of gas-exchange impairment in idiopathic pulmonary fibrosis. Am Rev Respir Dis 1991; 143: 219-225.

19. Ferris GB. Epidemiology standardization project. $A m$ Rev Respir Dis 1978; 118 (Suppl. 2): 55-110.

20. Xaubet A, Rodriguez-Roisin R, Bombí JA, Marín A, Roca J, Agustí-Vidal A. Correlation of bronchoalveolar lavage and clinical and functional findings in asbestosis. Am Rev Respir Dis 1986; 133: 848-854.

21. International Labour Office and Union Internationale Contre le Cancer. International classification of radiographs of pneumoconiosis. Geneva, International Labour Office, 1980; (Occupational Safety and Health Series, No. 22).

22. Cotes JE, Dabbs JM, Elwood PC, Hall AM, McDonald A, Saunders JM. Iron-defiency anaemia; its effect on transfer factor for the lung, diffusing capacity and ventilation and cardiac frequency during submaximal exercise. Clin Sci 1972; 42: 325-335.

23. Roca J, Sanchis J, Agustí-Vidal A, et al. Spirometric reference values for a Mediterranean population. Bull Eur Physiopathol Respir 1986; 22: 217-224.

24. Roca J, Rodriguez-Roisin R, Cobo E, Burgos F, Pérez J, Clausen JL. Single-breath carbon monoxide diffusing capacity (DLCO) prediction equations for a mediterranean population. Am Rev Respir Dis 1990; 140: 1026-1032.

25. Agustí AGN, Roca J, Rodriguez-Roisin R, Xaubet A, Agustí-Vidal A. Different patterns of gas exchange response to exercise in asbestosis and idiopathic pulmonary fibrosis. Eur Respir J 1988; 1: 510-515.

26. Jones NL, Makrides L, Hitchcock C, Chypchar T, McCartney N. Normal standards for an incremental progressive cycle ergometer test. Am Rev Respir Dis 1985; 131: 700-708.

27. Xaubet A, Roca J, Rodriguez-Roisin R, et al. Bronchoalveolar lavage cellular analysis and gallium lung scan in the assessment of patients with amiodaroneinduced pneumonitis. Respiration 1987; 52: 272-280.

28. Weinberger SE, Johnson TS, Weiss ST. Use and interpretation of the single-breath diffusing capacity. Chest 1980; 78: 483-488.

29. Quanjer PH. Standardized lung function testing. Bull Eur Physiopathol Respir 1983; 19 (Suppl. 5): 39-44.

30. American Thoracic Society. Single-breath carbon monoxide diffusing capacity (transfer factor). Recommendations for a standard technique. Am Rev Respir Dis 1987; 136: $1299-1307$.

31. American Thoracic Society. Lung function testing: selection of reference values and interpretative strategies. Am Rev Respir Dis 1991; 144: 1202-1218.

32. Reynolds HY. Idiopathic interstitial pulmonary fibrosis. Contribution of bronchoalveolar lavage analysis. Chest 1986; 89 (Suppl.): 3: 139S-144S. 